\title{
FREE VIBRATION ANALYSIS OF A LAMINATED COMPOSITE BEAM WITH VARIOUS BOUNDARY CONDITIONS
}

\author{
Murat Balcı $^{1}$, Mustafa Oğuz Nalbant ${ }^{1}$, Ercan $\operatorname{Kara}^{1}$ and Ömer Gündoğdu ${ }^{2}$ \\ ${ }^{1}$ Bayburt University, Faculty of Engineering, \\ Mechanical Engineering, \\ Bayburt, Turkey. \\ Phone: +90-458-2111178 \\ Email: mbalci@bayburt.edu.tr \\ ${ }^{2}$ AtatürkUniversity, Faculty of Engineering, \\ Mechanical Engineering, Erzurum, Turkey.
}

\begin{abstract}
This study presents a free vibration analysis of a laminated composite beam, based on the Euler-Bernoulli beam theory. A numerical model of the laminated composite beam was obtained for various boundary conditions based on different length-to-thickness ratios for a number of layers, using the finite element method. A planar beam bending element with two nodes, each having two degrees of freedom, was chosen according to Euler-Bernoulli beam theory. The natural frequencies of the laminated composite beam were obtained for each case, and presented in such a way as to display the effect of these changes on the natural frequencies. Eight natural frequencies of clamped-free, clamped-clamped (CC) and simple-simple (SS) composite beams were first obtained for different length-to-thickness ratios $\left(\mathrm{L}_{\mathrm{x}} / \mathrm{h}\right)$, numbers of layers, layer angles and for their different positions. It can be seen that natural frequencies decrease for all modes with increasing length-to-thickness ratio in all cases.
\end{abstract}

Keywords: Finite element method; Laminated composite beam; Euler-Bernoulli beam; free vibration.

\section{INTRODUCTION}

The use of composites as engineering materials has increased greatly in recent years. They took the place of other engineering materials due to their strength, light weight, resistance to corrosion and wear, and other superior properties. These physical properties thus need to be known in order to be analyzed and structurally designed. A variety of composite materials have been investigated in the literature, and in this study, laminated composite materials have been chosen for research. Having a high strength/weight ratio, these materials are produced through a range of plys, which have orthotropic features, one on top of another, with different angles and forms. Their mechanical properties are thus related to their forms and angles. For this reason, it is possible to make produce the desired properties for different loading conditions. On the other hand, the analyses of these materials is more complicated than that of isotropic materials because of their anisotropic structures. It is necessary to analyze the free vibration behaviors of the laminated composite materials used in various engineering fields. Many researchers have tackled the vibration problem of laminated composites. For instance Thambiratnam and Zhuge (1996) implemented a finite element model to 
undertake a free vibration analysis of isotropic beams with uniform cross sections on an elastic foundation using Euler-Bernoulli beam theory. Huang, Shih, and Kim (2009) attempted to use an inverse vibration method to solve the forced vibration problem raised in cutting tools that were modeled as Euler-Bernoulli beams. In numerical solutions, the conjugate gradient method was utilized, and simulation results for the beam displacements were used to estimate external forces on the cutting tool. Della and Shu (2005) analytically solved the free vibration problem of composite beams with two overlapping delaminations. In their study, various boundary conditions were investigated, natural frequencies and mode shapes were obtained, and they compared their results with experimental findings. Miller and Adams (1975) investigated the effects of shear deformation on the free vibration of an orthotropic cantilever beam, studying the free vibration analysis of orthotropic clamped free beams, using the EulerBernoulli beam theory without including the effect of shear deformation. Free vibration analysis of a cross-ply laminated composite beam on Pasternak foundation was investigated. Natural frequencies of beams on Pasternak foundations were computed using the finite element method on the basis of Timoshenko beam theory by JafariTalookolaei and Ahmadian (2007). The effects of delamination length and orientation angle on the natural frequency of symmetric composite beams were investigated analytically and numerically. The analytical method was developed using the Timoshenko beam theory by (Çallioğlu \& Atlihan, 2011). In this paper, the effect of changes in boundary conditions and ply angles on the natural frequencies of layered composite beams were investigated, based on length-to-thickness ratios. The finite element method was used for the analysis with the Euler-Bernoulli beam assumption. A MATLAB program was developed to solve the problem. The first eight frequencies were computed and presented both in tabular form and as graphics.

\section{CLASSICAL LAMINA BEAM THEORY (CLBT)}

Euler-Bernoulli beam theory, also known as the Classical Lamina Beam Theory (CLBT), neglects the transverse shear deformation and normal strain effects (Özutok \& Madenci, 2013). The geometry of the composite laminated beam is shown in Figure 1. Figure 2 shows the coordinates and geometry of laminated composite beam.

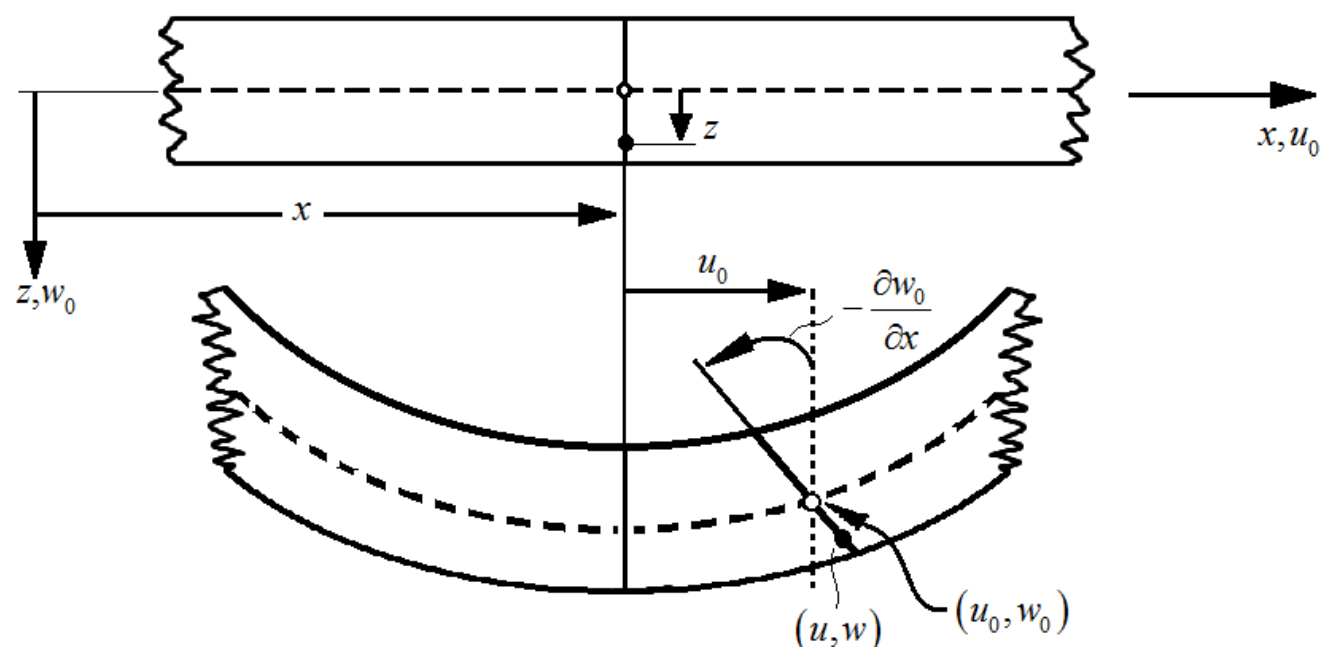

Figure 1. Euler-Bernoulli beam theory (Wang, Reddy, \& Lee, 2000) 


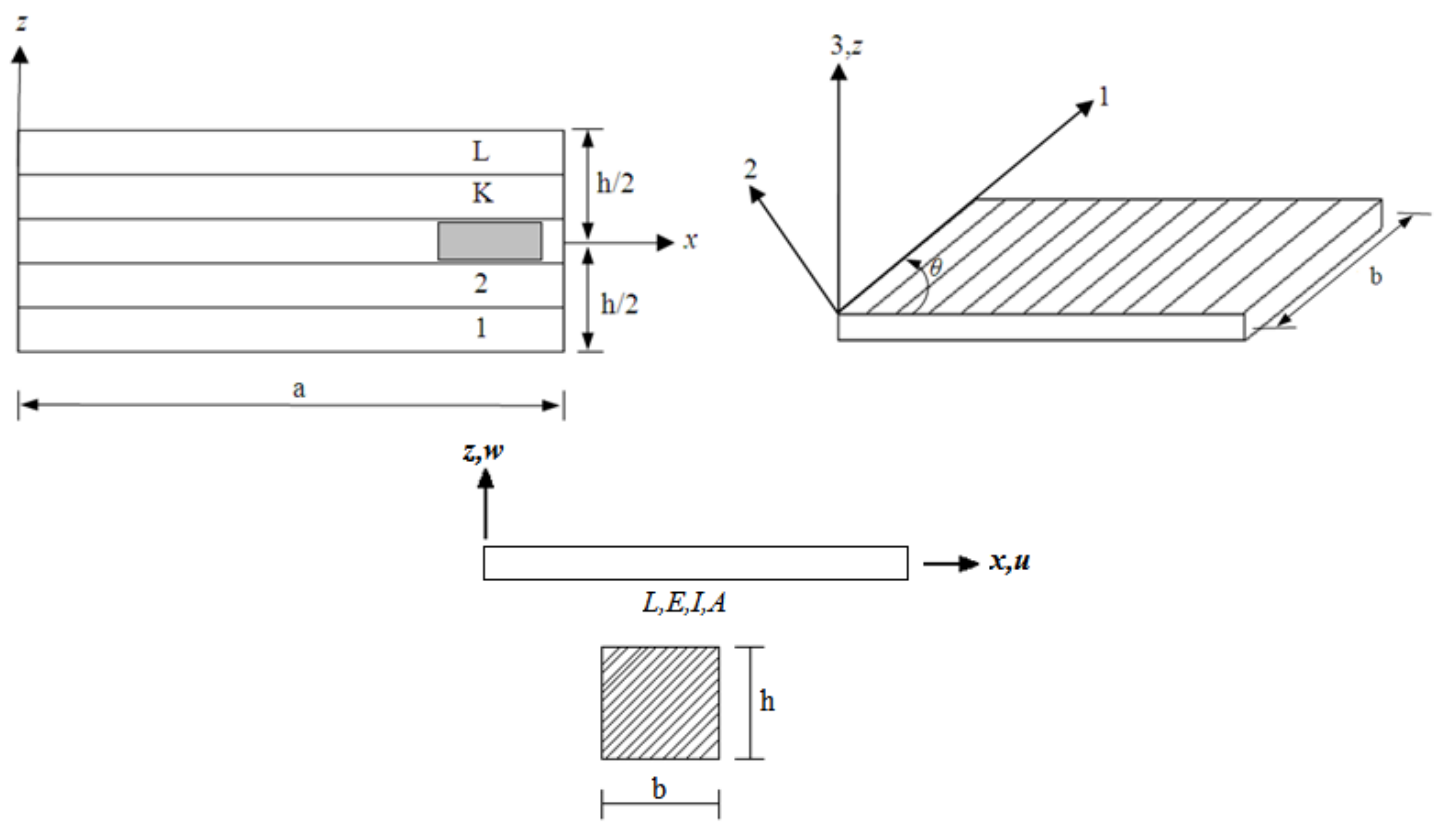

Figure 2. Coordinates and geometry of laminated composite beam

The relationship between the strain $\varepsilon$ and the axial displacement $u$ is given by: (Petyt, 1990)

$$
\varepsilon=\frac{d u}{d x}
$$

The relationship between the axial displacement $u$ and the rotation of the cross-section $\theta$ is obtained as: (Petyt, 1990)

$$
d u=-z d \theta
$$

The relationship between the deflection of beam $w$ and the rotation of the cross-section $\theta$ can be written as

$$
\theta \cong \frac{d w}{d x}
$$

from the Euler-Bernoulli beam theory (Wang et al., 2000). If the Eq. (3) and (2) are substituted into Eq. (1),

$$
\varepsilon=-z \frac{d^{2} w}{d x^{2}}
$$

can be obtained (Wang et al., 2000). The curvature of the beam from Eq. (4) can be written as: (Petyt, 1990)

$$
\kappa=\frac{d^{2} w}{d x^{2}}
$$




\section{MATHEMATICAL MODEL OF LAMINATED COMPOSITE BEAM}

Figure 3 presents the geometry of laminated composite beam. The stress-strain relationship for a laminated composite Euler-Bernoulli beam is given by Hooke's law as: (Wang et al., 2000)

$$
\{\sigma\}=[D]\{\varepsilon\}
$$

where $[D]$ is a bending stiffness matrix, and $\sigma$ represents the stress. The material was assumed to be linear orthotropic.

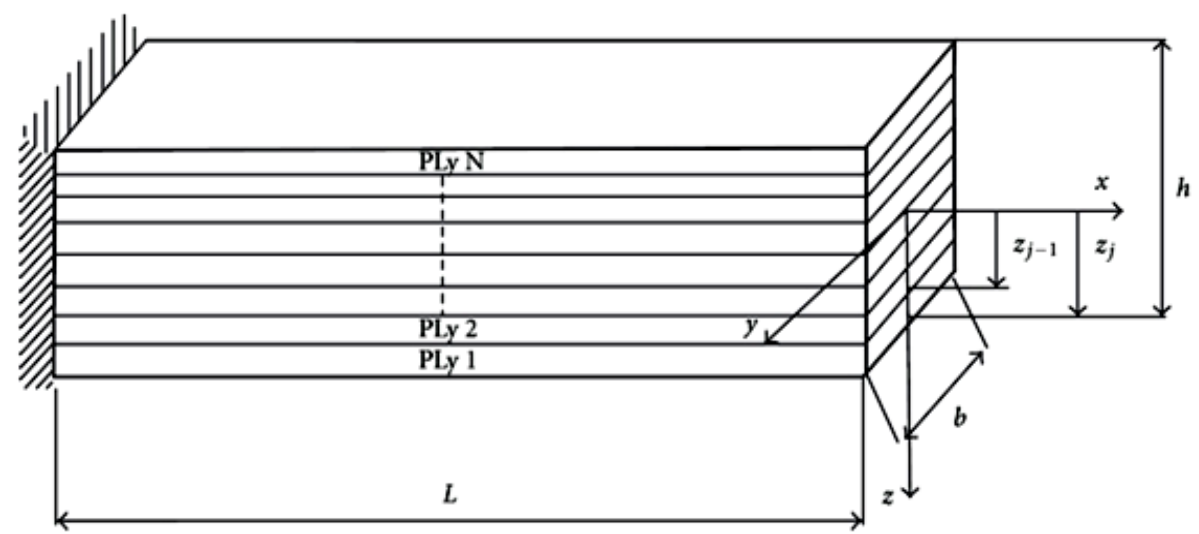

Figure 3. Geometry of laminated composite beam (Atlihan et al., 2009)

Each term in Eq. (6) is defined as the following: (Kollár \& Springer, 2003)

$$
\begin{aligned}
& \{\sigma\}^{i}=\left[\begin{array}{lll}
\sigma_{x} & \sigma_{y} & \tau_{x y}
\end{array}\right]^{T^{i}} \\
& \{\varepsilon\}^{i}=\left\{\begin{array}{lll}
\varepsilon_{x} & \varepsilon_{y} & \gamma_{x y}
\end{array}\right\}^{T^{i}} \\
& {[Q]^{i}=\left[\begin{array}{ccc}
Q_{11} & Q_{12} & 0 \\
Q_{12} & Q_{22} & 0 \\
0 & 0 & Q_{66}
\end{array}\right]^{i}} \\
& \text { (Manning) }
\end{aligned}
$$

$[Q]^{i}$ represents the reduced elastic constants matrix for the $\mathrm{i}^{\text {th }}$ layer, which is given in Eq. (Manning) as: (Reddy, 2004)

$$
\begin{aligned}
& Q_{11}=\frac{E_{1}}{1-v_{12} v_{21}}, \quad Q_{12}=\frac{v_{12} E_{2}}{1-v_{12} v_{21}} \\
& Q_{22}=\frac{E_{2}}{1-v_{12} v_{21}}, \quad Q_{66}=G_{12}
\end{aligned}
$$




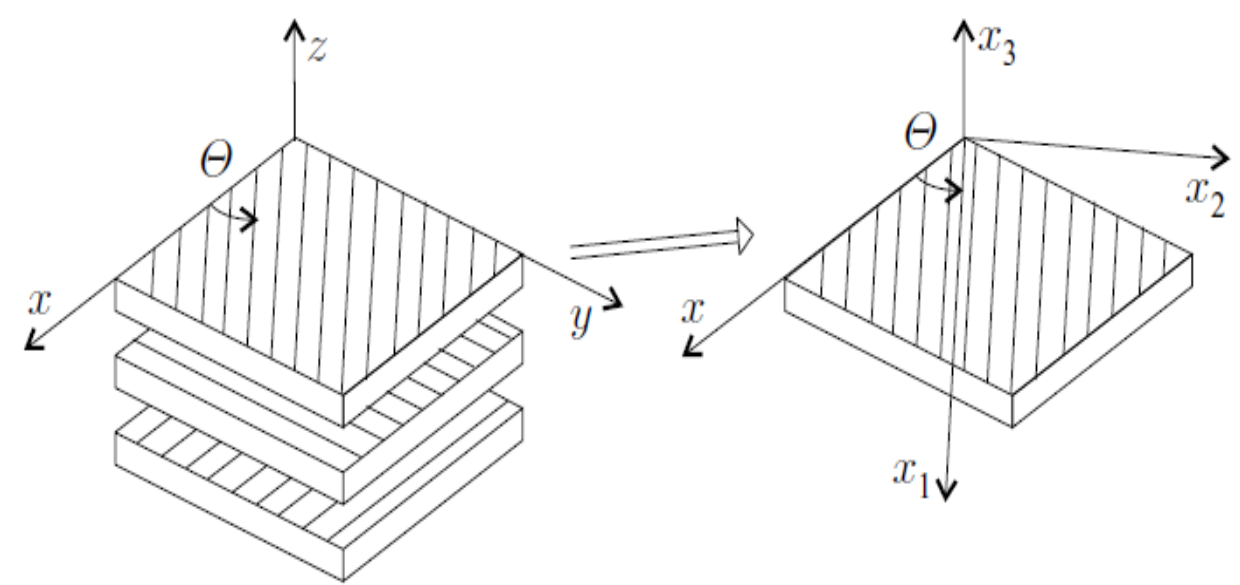

Figure 4. The $x, y, z$ laminate coordinate system, the $\mathrm{x}_{1}, \mathrm{x}_{2}, \mathrm{x}_{3}$ ply coordinate system, and the ply angle (Kollár \& Springer, 2003)

$$
[\sigma]_{x_{1}-x_{2}}=[T][\sigma]_{x-y}
$$

(Papuga)

where $[T]$ is the transformation matrices for stress and strain, respectively.

Where the elements in the stiffness matrix, $[\bar{Q}]$ matrix is

$$
[\bar{Q}]=[T][Q][T]^{T}
$$

(Wang et al.)

The stiffness matrices of the laminate are defined as: (Kollár \& Springer, 2003)

$$
A_{i j}=\sum_{k=1}^{N} \bar{Q}_{i j}{ }^{(k)}\left(z_{k}-z_{k-1}\right) \quad B_{i j}=\frac{1}{2} \sum_{k=1}^{N} \bar{Q}_{i j}{ }^{(k)}\left(z_{k}^{2}-z_{k-1}^{2}\right) \quad D_{i j}=\frac{1}{3} \sum_{k=1}^{N} \bar{Q}_{i j}{ }^{(k)}\left(z_{k}^{3}-z_{k-1}^{3}\right)
$$

The geometric and physical properties of the laminated composite beam used in MATLAB are provided in Table 1.

Table 1. Geometric and physical properties of laminated composite beam (Balci, 2011).

$$
\begin{array}{lll}
\hline E_{x}=38 \mathrm{GPa} & E_{y}=3.8 \mathrm{GPa} & E_{z}=3.8 \mathrm{GPa} \\
G_{x y}=1.9 \mathrm{GPa} & G_{x z}=1.9 \mathrm{GPa} & G_{y z}=0.76 \mathrm{GPa} \\
v_{x y}=0.25 & v_{y z}=0.25 & \rho=1295 \mathrm{~kg} / \mathrm{m}^{3} \\
L_{x}=1 \mathrm{~m} & b=0.01 \mathrm{~m} & \\
\hline
\end{array}
$$

\section{FINITE ELEMENT MODEL}

A planar beam bending element with two nodes, each having two-degree-of-freedom, was chosen, obeying Euler-Bernoulli beam theory. The beam element, with the same 
degree of freedom as beam deflection $w$ and the rotation of the cross-section $\theta$, is depicted in Figure 5.

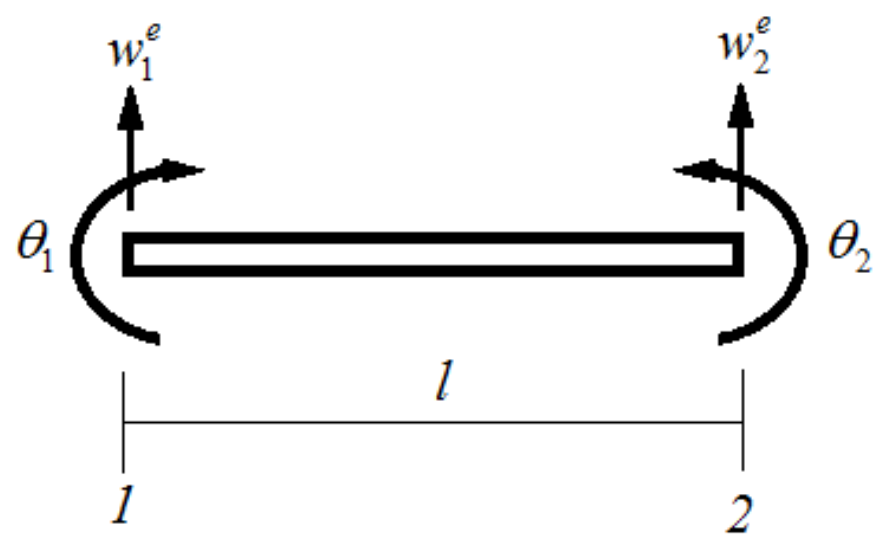

Figure 5. Plane beam bending element (Balci, 2011)

The potential energy for a laminated composite beam element in bending vibration is given as: (Lee, 1988).

$$
U=\sum_{e} \frac{1}{2}\{q\}^{T}\left[t \int_{-1}^{1}[B]^{T}[D][B] \partial x\right]\{q\}
$$

The kinetic energy of a laminated composite beam element in bending vibration is: (Lee, 1988).

$$
T_{e}=\frac{1}{2}\{\dot{q}\}^{T}\left|\int_{e} \rho[N][N]^{T} \partial v\right|\{\dot{q}\}
$$

If the potential and kinetic energy expressions are substituted in the Hamilton principle: (Petyt, 1990)

$$
L=\int_{t_{0}}^{t_{1}} \delta(T-U) d t+\int_{t_{0}}^{t_{1}} \delta W d t
$$

is obtained, where $W$ expresses the work done by external forces. If Eq. (Manning) is minimized for a system under undamped free vibration, the equation of motion of a beam undergoing bending vibrations can be obtained as: (Balci, 2011)

$$
\left[m^{e}\right]\left\{\ddot{q}^{e}\right\}+\left[k^{e}\right]\{q\}=0
$$

where $\left[m^{e}\right]$ and $\left[k^{e}\right]$ are the mass and stiffness matrices, respectively. If the curvature of the Euler-Bernoulli beam is re-written

$$
\kappa=\frac{d^{2} w}{d x^{2}}=\frac{d^{2}}{d x^{2}}\{w\} \rightarrow \kappa=\boldsymbol{D} w
$$

where $\boldsymbol{D}$ is the linear differential operator and $\boldsymbol{w}$ displacement, beam displacement equation is then: (Kollar and Springer, 2003) 


$$
w=N d
$$

where $\boldsymbol{N}$ represents shape function and $\boldsymbol{d}$ nodal displacement operator. The nodal displacement operator is given as

$$
\boldsymbol{d}=\left\{\begin{array}{c}
w_{i} \\
\frac{d w_{i}}{d x}
\end{array}\right\}=\left\{\begin{array}{c}
w_{i} \\
\theta_{i}
\end{array}\right\}
$$

If the Eq. (19) is substituted in Eq. (18) the expression

$$
\kappa=D w=D N d \rightarrow \kappa=B d
$$

is obtained [24], where the expression $\boldsymbol{B}$ is the strain-displacement matrix. If the stiffness matrix for the bending laminated composite beam element is: (Lee, 1988).

$$
[k]_{e}=t \int_{-1}^{1}[B]^{T}[D][B] \partial x
$$

The mass matrix for the bending laminated composite beam element is (Lee, 1988).

$$
\left[m_{e}\right]=\int_{e} \rho[N]^{T}[N] \partial V
$$

If the mass and stiffness matrices developed for the bending beam element are combined so as to represent an Euler-Bernoulli beam,

$$
\begin{aligned}
& {[M]=\sum_{e=1}^{n} m^{e}} \\
& {[K]=\sum_{e=1}^{n} k^{e}}
\end{aligned}
$$

are obtained, where the matrices $[\mathrm{M}]$ and $[\mathrm{K}]$ are respectively the global mass and stiffness matrices, and $n$ the number of finite elements used in the model.

\section{DEVELOPMENT OF SHAPE FUNCTION}

The plain beam element shown in Figure 5 has two nodes with two degrees of freedom, and thus it has four degrees of freedom in total. To determine shape function, a cubic polynomial with four terms for each degree of freedom has been chosen as the displacement shape function from the Pascal triangle shown in Figure 6.

$$
w(x)=a_{1}+a_{2} x+a_{3} x^{2}+a_{4} x^{3}
$$

Beam displacement can be written in the following form: (De Abreu, Ribeiro, \& Steffen Jr, 2004)

$$
w=\{P\}^{\mathrm{T}}\{a\}
$$


In Eq. (25), $a$ is the coefficient vector and $P$ is the interpolation polynomial term vector. The coefficient and interpolation polynomial term vectors are given in the following format (De Abreu et al., 2004)

$$
\begin{aligned}
& \{a\}=\left\{\begin{array}{llll}
a_{1} & a_{2} & a_{3} & a_{4}
\end{array}\right\}^{\mathrm{T}} \\
& \{P\}=\left\{\begin{array}{llll}
1 & x & x^{2} & x^{3}
\end{array}\right\}^{\mathrm{T}}
\end{aligned}
$$

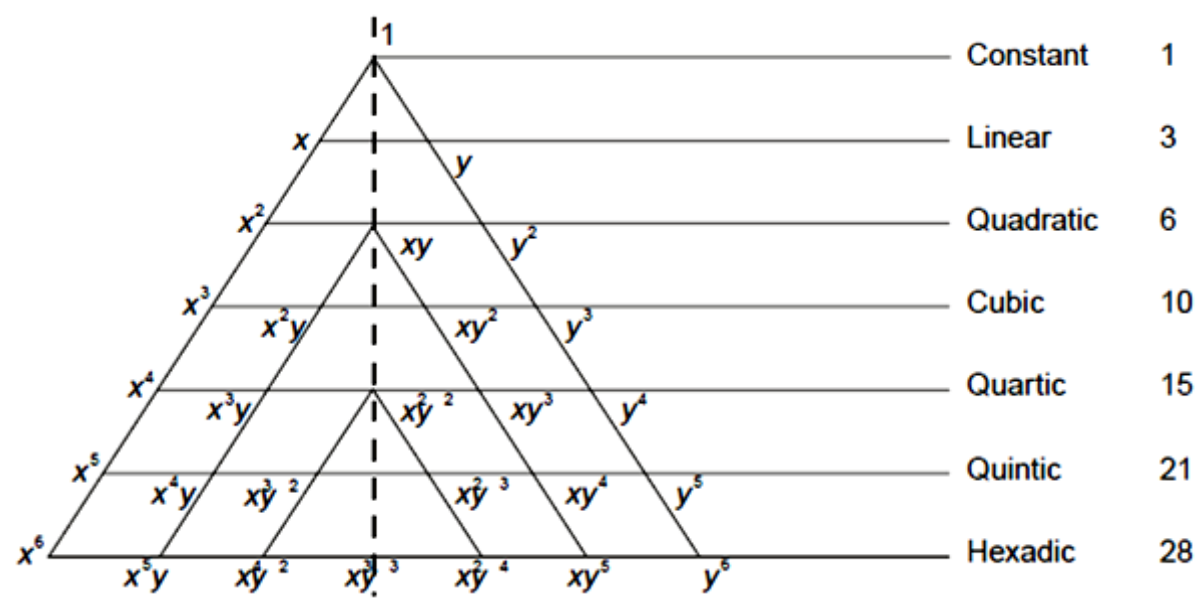

Figure 6. Pascal Triangle (Bhavikatti, 2005)

If the displacement polynomial given in Eq. (24) is substituted into Eq. (18) in a matrix form and expanded for each node: (Abreu, Riberio, \& Steffen, 2004),

$$
\{\boldsymbol{d}\}=[X]\{a\}
$$

is obtained. $X$ in Eq. (27) represents the expanded displacement matrix of dimension $4 \times 4$. Then, Eq. (27) is solved for the coefficient vector:

$$
\{a\}=[X]^{-1}\{d\}
$$

If Eq. (28) is substituted in Eq. (25), one may obtain:

$$
w=\{P\}^{\mathrm{T}}[X]^{-1}\{\boldsymbol{d}\}
$$

If Eq. (29) is substituted in Eq. (28) and reorganized, the shape function is developed in the form below:

$$
\boldsymbol{N}=\{P\}^{\mathrm{T}}[X]^{-1}
$$

\section{DYNAMICS ANALYSIS}

The equation of motion for the beam undergoing undamped free vibration was given in Eq. (16). The equation of motion for the global system is 


$$
[M]\{\ddot{q}\}+[K]\{q\}=0
$$

for which a harmonic solution can be proposed in the following form:

$$
\{q\}=\{\psi\} \sin (\omega t)
$$

If Eq. (32) is substituted into Eq. (31)

$$
-[M]\{\psi\} \omega^{2} \sin (\omega t)+[K]\{\psi\} \sin (\omega t)=0
$$

is obtained. If Eq. (33) is further reorganized, it takes the following eigenvalue problem of the form

$$
\left([K]-\omega^{2}[M]\right)\{\psi\}=0
$$

where $\lambda=\omega^{2}$ are eigenvalues representing vibration frequencies while $\psi$ are eigenvectors representing vibration modes (Balci, 2011).

\section{RESULTS AND DISCUSSION}

A numerical model for the laminated composite beam problem was constructed in MATLAB with clamped-free (Chirn \& McFarlane, 2000), clamped-clamped (CC), and simple-simple supported (SS) boundary conditions. Laminated composite beams with four layers having [0/90/90/0] and [-45 4545 -45] also two layers having [-45 45] and six layers having [ $\left[\begin{array}{llll}0 & -45 & 45 & -45\end{array}\right]$ ] orientation angles were used for natural frequency analysis. As shown in Table 2 and Figure 7, it is understood that when length-tothickness ratio increases, natural frequency decreases. That result is the same for all modes analyzed in this study.

Table 2. Natural Frequency (Hz) estimates for (Chirn \& McFarlane) laminated composite beam with four layers having [0/90/ 90/0].

\begin{tabular}{ccccccccc}
\hline \multirow{2}{*}{$L_{x} / h$} & \multicolumn{7}{c}{ Free Natural Vibration Frequencies $(\mathrm{Hz})$} \\
\cline { 2 - 9 } & Mode & Mode & Mode & Mode 4 & Mode 5 & Mode 6 & Mode 7 & Mode 8 \\
& 1 & 2 & 3 & & & & & \\
\hline 20 & 41.3 & 258.7 & 724.3 & 1419.4 & 2346.4 & 3505.1 & 4895.6 & 6517.8 \\
50 & 16.5 & 103.5 & 289.7 & 567.8 & 938.6 & 1402.1 & 1958.2 & 2607.1 \\
100 & 8.3 & 51.7 & 144.9 & 283.9 & 469.3 & 701 & 979.1 & 1303.6 \\
& 4.127 & 25.869 & 72.434 & 141.943 & 234.642 & 350.514 & 489.562 & 651.783 \\
200 & 9 & 3 & 7 & 1 & 2 & 8 & 0 & 7 \\
& 2.750 & 17.239 & 48.270 & 94.5909 & 156.365 & 233.583 & 326.244 & 434.348 \\
300 & 8 & 3 & 5 & 5 & 1 & 1 & 7 \\
& 2.064 & 12.934 & 36.217 & 70.9716 & 117.321 & 175.257 & 244.781 & 325.891 \\
400 & 0 & 6 & 4 & & 1 & 4 & 0 & 8 \\
& 1.651 & 10.347 & 28.973 & 56.7773 & 93.8569 & 140.205 & 195.824 & 260.713 \\
500 & 2 & 7 & 9 & 56.773 & 9 & 8 & 5 \\
\hline
\end{tabular}


When the layer angles changed from 45 degree to 90, it was observed that the natural frequency increases, as can be seen in Figure 9. The simulation results obtained for the CF laminated composite beam with four layers [-45/45/ 45/ -45] are shown in Table 3 and Figure 8. The number of layers were compared and it was observed that natural frequencies for first mode increased with the number of layers increasing, as seen in in Figure10.

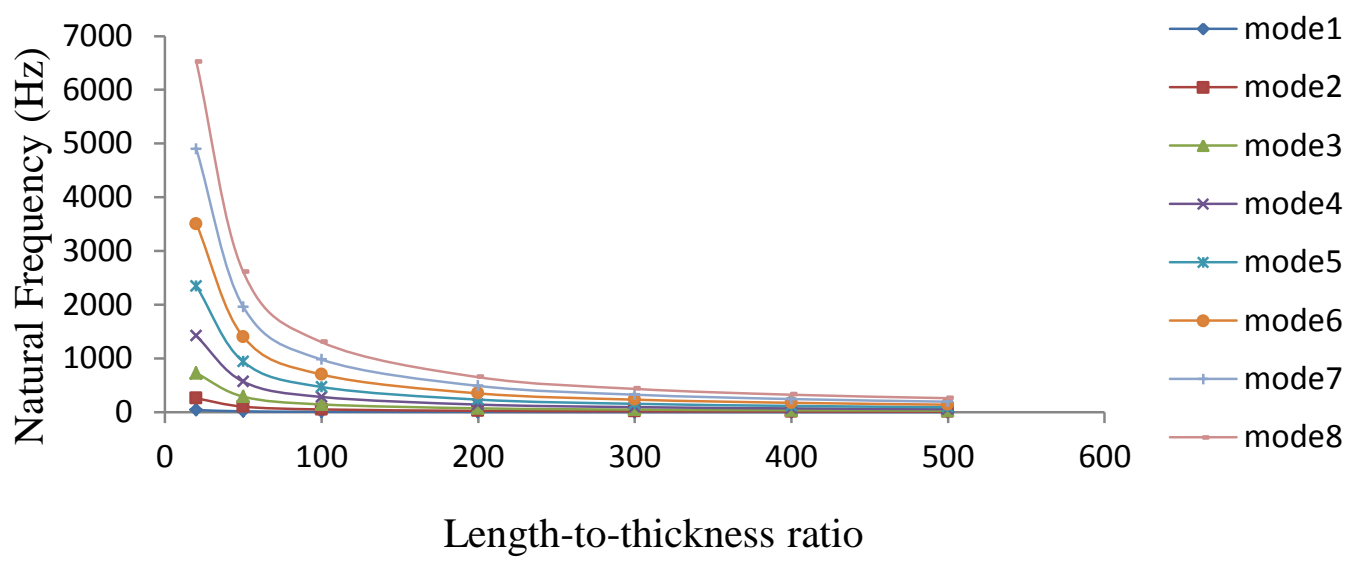

Figure 7. Natural Frequency (Hz) graph for (Chirn \& McFarlane) laminated composite beam with four layers having [0/90/90/0]

Table 3. Natural Frequency (Hz) estimates for (Chirn \& McFarlane) laminated composite beam with four layers having [-45/45/45/-45].

\begin{tabular}{ccccccccc}
\hline \multirow{2}{*}{$L_{x} / h$} & \multicolumn{7}{c}{ Free Vibration Natural Frequencies (Hz) } \\
\cline { 2 - 8 } & Mode & Mode & Mode & Mode 4 & Mode 5 & Mode 6 & Mode 7 & Mode 8 \\
\hline 20 & 1 & 2 & 3 & & & & & \\
& 17.3 & 108.5 & 303.8 & 595.3 & 984 & 1470 & 2053.1 & 2733.4 \\
50 & 6.9 & 43.4 & 121.5 & 238.1 & 393.6 & 588 & 821.2 & 1093.4 \\
& 3.462 & 21.697 & 60.754 & 119.054 & 196.805 & 293.992 & 410.617 & 546.680 \\
100 & 3 & 7 & 3 & 2 & 1 & 7 & 9 & 6 \\
& 1.731 & 10.848 & 30.377 & 59.5271 & 98.4025 & 146.996 & 205.309 & 273.340 \\
200 & 2 & 9 & 1 & & 4 & 0 & 3 \\
& 1.153 & 7.2297 & 20.243 & 39.6688 & 65.5755 & 97.9584 & 136.817 & 182.154 \\
300 & 6 & 3 & & & & 9 & 0 \\
& 0.855 & 5.4244 & 15.188 & 29.7635 & 49.2013 & 73.4982 & 102.654 & 136.670 \\
400 & 6 & 6 & & & & 5 & 2 \\
& 0.692 & 4.3395 & 12.150 & 23.8108 & 39.3610 & 58.7985 & 82.1236 & 109.336 \\
500 & 4 & 9 & & & & & & 1 \\
\hline
\end{tabular}




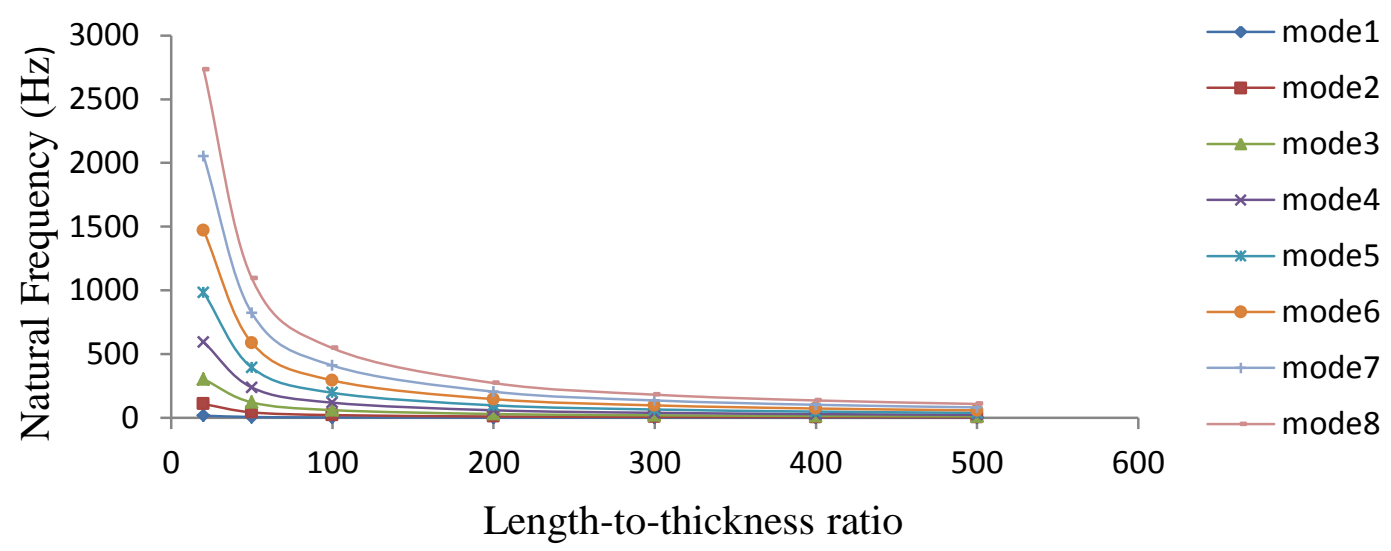

Figure 8. Natural frequency $(\mathrm{Hz})$ estimates for (Chirn \& McFarlane) laminated composite beam with four layers having [-45/45/45/-45]

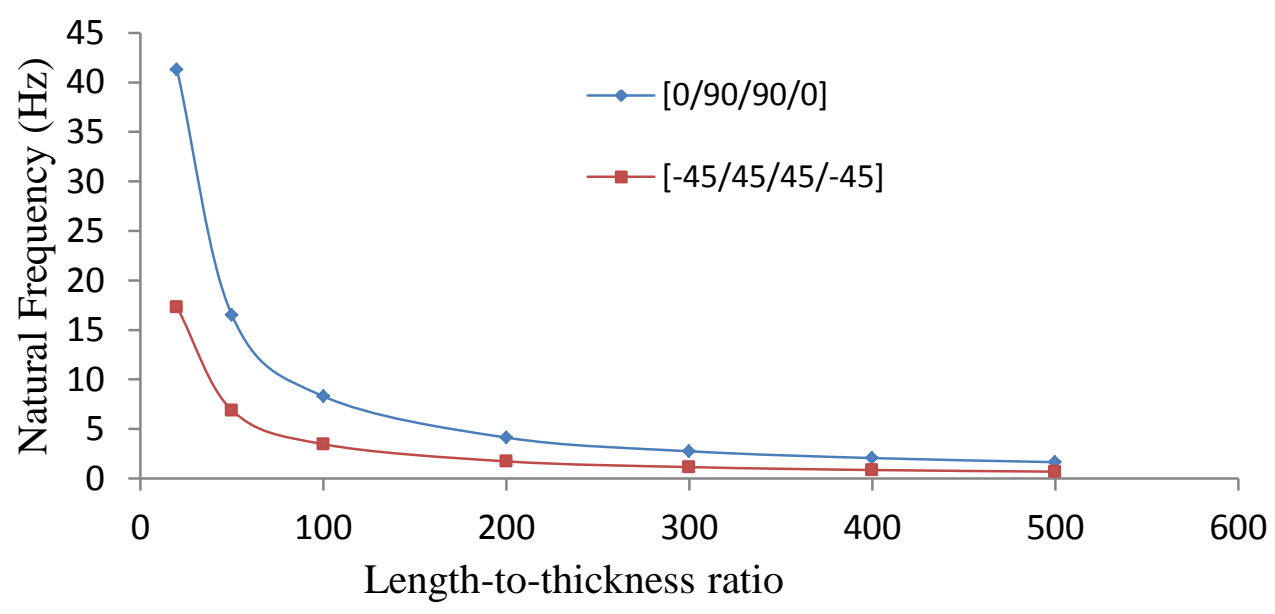

Figure 9. Natural Frequencies (Hz) compared [0 9090 0] to [-45 4545 -45] for (Chirn $\&$ McFarlane) laminated composite beam

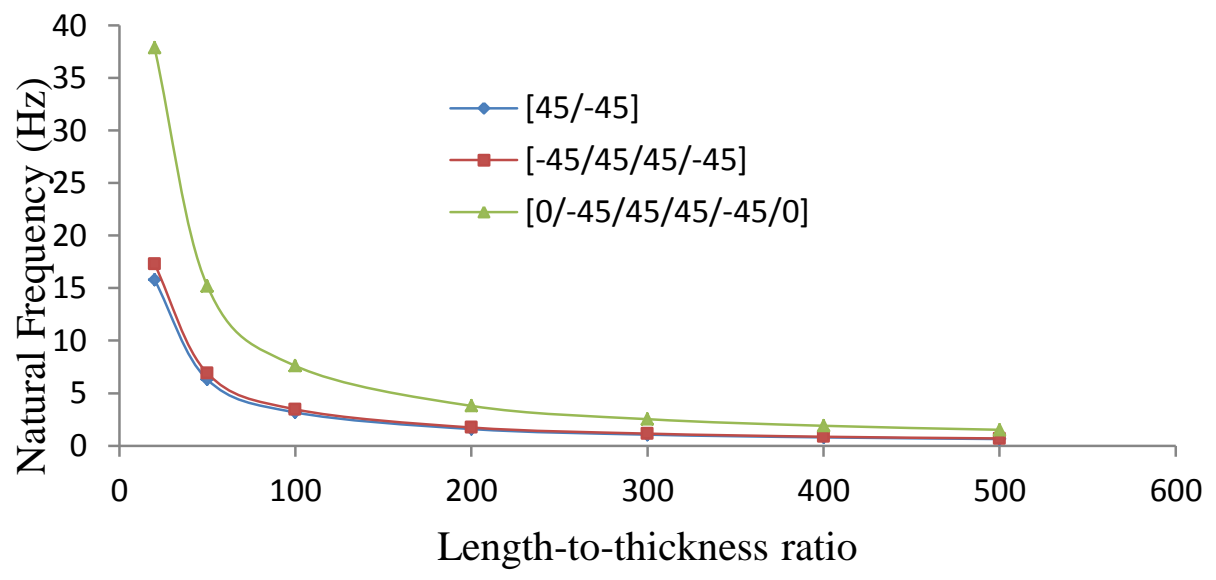

Figure 10. Natural Frequencies (Hz) compared to two, four and six layers

\section{CONCLUSIONS}

In this study, the free vibrations of a laminated composite beam were studied using classical lamination theory for different boundary conditions and length-to-thickness ratios for a number of layers. A finite element model of the beam was developed and 
solved in MATLAB to analyze the free vibration of the beam. The first eight natural frequencies of clamped-free, clamped-clamped and simple-simple composite beams were obtained for different length-to-thickness ratios $\left(\mathrm{L}_{\mathrm{x}} / \mathrm{h}\right)$, numbers of layers, layer angles and for their different positions. It can be seen that natural frequencies for all modes decrease with an increase in length-to-thickness ratio for all cases. It was observed that natural frequency increases when the boundary condition of the beam changed from respectively clamped-free, simple-simple and clamped-clamped. The natural frequencies for the first mode also increased with the increasing number of layer. In future work the mode shapes will be estimated in graphical form for laminated composite beams with different boundaries and number of layers.

\section{REFERENCES}

Abreu, G. L. C. M., Riberio, J. F., \& Steffen, V. (2004). Finite element modeling of a plate with localized piezoelectric sensors and actuators. Journal of the Brazilian Society of Mechanics Science \& Engineering, 26(2), 117-128.

Balci, M. (2011). Estimation of physical properties of laminated composites via the method of inverse vibration problem. ( $\mathrm{PhD}$ Thesis), Ataturk University, Graduate School of Natural and Applied Sciences, Erzurum.

Bhavikatti, S. S. (2005). Finite element analysis (Vol. 334). New Delhi: New Age International Limited.

Çallioğlu, H., \& Atlihan, G. (2011). Vibration analysis of delaminated composite beams using analytical and fem models. Indian Journal of Engineering \& Materials Sciences, 18, 7-14.

Chirn, J. L., \& McFarlane, D. C. (2000, 2000). A holonic component-based approach to reconfigurable manufacturing control architecture. Paper presented at the 11th International Workshop on Database and Expert Systems Applications.

De Abreu, G., Ribeiro, J., \& Steffen Jr, V. (2004). Finite element modeling of a plate with localized piezoelectric sensors and actuators. Journal of the Brazilian Society of Mechanical Sciences and Engineering, 26(2), 117-128.

Della, C. N., \& Shu, D. (2005). Free vibration analysis of composite beams with overlapping delaminations. European Journal of Mechanics-A/Solids, 24(3), 491-503.

Huang, C.-H., Shih, C.-C., \& Kim, S. (2009). An inverse vibration problem in estimating the spatial and temporal-dependent external forces for cutting tools. Applied Mathematical Modelling, 33(6), 2683-2698.

Jafari-Talookolaei, R., \& Ahmadian, M. (2007). Free vibration analysis of a cross-ply laminated composite beam on pasternak foundation. Journal of Computer Science, 3(1), 51-56.

Kollár, L. P., \& Springer, G. S. (2003). Mechanics of composite structures: Cambridge university press.

Lee, M.-H. (1988). Finite element analysis of laminated composite plates. California: Naval Postgraduate School Monterey.

Manning, R., Ewing, J. (2009). .RACQ Vehicles Technologies. (2009). Temperatures in cars survey. RACQ Vehicles Technologies, 1-21.

Miller, A., \& Adams, D. (1975). An analytic means of determining the flexural and torsional resonant frequencies of generally orthotropic beams. Journal of Sound and Vibration, 41(4), 433-449. 
Özutok, A., \& Madenci, E. (2013). Free vibration analysis of cross-ply laminated composite beams by mixed finite element formulation. International Journal of Structural Stability and Dynamics, 13(02), 1250056.

Papuga, J. (2011). A survey on evaluating the fatigue limit under multiaxial loading. International Journal of Fatigue, 33, 153-165.

Petyt, M. (1990). Introduction to finite element vibration analysis: Cambridge university press.

Reddy, J. N. (2004). Mechanics of laminated composite plates and shells: Theory and analysis: CRC press.

Thambiratnam, D., \& Zhuge, Y. (1996). Free vibration analysis of beams on elastic foundation. Computers \& Structures, 60(6), 971-980.

Wang, C., Reddy, J. N., \& Lee, K. (2000). Shear deformable beams and plates: Relationships with classical solutions: Elsevier.

Wang, J., Lu, M. X., Zhang, L., Chang, W., Xu, L. N., \& Hu, L. H. (2012). Effect of welding process on the microstructure and properties of dissimilar weld joints between low alloy and duplex stainless steel. International Journal of Minerals, Metallurgy and Materials, 19(6), 518-524. 